\title{
A INFLUÊNCIA DA TV JUSTIÇA NO PROCESSO DECISÓRIO DO STF //
}

\author{
Ivar Alberto Hartmann ${ }^{1}$, Guilherme da Franca Couto Fernandes de Almeida ${ }^{2}$, Beatriz Nunes \\ Valim $^{3}$, Clarissa Emanuel Leão Lima ${ }^{4}$, Gabriel Borges Mariano ${ }^{5}$, José Luiz Nunes ${ }^{6}$ e Larissa \\ de Lima e Campos ${ }^{7}$
}

\section{Palavras-chave}

Direito Constitucional / argumentação jurídica / STF / TV Justiça / deliberação judicial

HIIIIIIIIIIIIIIIIIIIIIIIIIIIIIIIIII

\section{Sumário}

1 Introdução

2 O debate sobre o televisionamento

2.1 Argumentos pró-televisionamento/ publicidade

2.2 Argumentos contra o televisionamento/ publicidade

3 Hipóteses

4 Método

4.1 Dados

4.2 Variáveis

\section{Resultados}

5.1 As decisões e os debates aumentaram após a TV Justiça?

5.2 É possível atribuir essa diferença à TV Justiça?

5.3 É possível que isso seja um mero efeito do tempo?

5.4 Modelos agregados

6 Conclusão

7 Referências

8 Apêndicas

\section{Resumo}

Diversos autores têm especulado sobre a influência da TV Justiça sobre o processo decisório do STF. Da mesma forma, os próprios ministros tendem a atribuir certos efeitos percebidos no comportamento argumentativo do tribunal ao televisionamento das sessões plenárias. Em geral, há um grau consideravelmente alto de convergência em torno de proposiç̃es como: "A partir da transmissão das sessões do STF, os ministros passaram a emitirvotos mais longos" e "A exposição excessiva do debate gera uma deliberação interna menos franca". O propósito do presente artigo é apresentar novas evidências empíricas sobre a TV Justiça, de modo a avaliar as afirmações que a literatura pré-existente faz sobre o tema. Em um nível mais básico, é preciso saber se a TV Justiça fez ou não diferença sobre o comportamento deliberativo dos ministros. Nossos resultados indicam que de fato há uma relação entre a transmissão das sessões plenárias do STF e um aumento no número de páginas das decisões. Da mesma forma, o televisionamento parece ter aumentado a extensão dos debates que os ministros travam entre si. Por fim, análises envolvendo modelos de regressão linear indicam que o resultado se mantém mesmo quando controlamos para outros fatores que influenciam sobre essas duas variáveis.

\footnotetext{
1 Professor da FGV Direito Rio. Coordenador do projeto Supremo em Números. E-mail: ivar.hartmann@fgv.br.

2 Bacharel em Direito pela UFRJ. Doutorando em Teoria do Estado e Direito Constitucional pelo PPGD da PUC-Rio. Pesquisador do projeto Supremo em Números, da FGV Direito Rio. E-mail: almeida2808@gmail.com.

3 Graduanda em Direito pela FGV Direito Rio.E-mail: valimbeatriz@ gmail.com.

4 Graduanda em Direito pela FGV Direito Rio. Assistente de pesquisa do FGV/CERI (Centro de Regulação e Infraestrutura). E-mail: claemanuela@hotmail.com.

5 Graduando em Direito pela FGV Direito Rio. E-mail: gabriel.mariano2014@fgvmail.br.

6 Graduando em Direito pela FGV Direito Rio. E-mail: jlnunes08@ gmail.com.

7 Graduanda em Direito pela FGV Direito Rio. Estagiária na área de Mercado de Capitais no escritório Eizirik Advogados. E-mail: larylcampos@yahoo.com.br.
} 


\section{THE INFLUENCE OF "TV JUSTIÇA" IN STF'S DECISION-MAKING PROCESS // Ivar Alberto Hartmann, Guilherme da Franca Couto Fernandes de Almeida, Beatriz Nunes Valim, Clarissa Emanuel Leão Lima, Gabriel Borges Mariano, José Luiz Nunes and Larissa de Lima e Campos}

\section{Keywords}

Constitutional Law / judicial argumentation / STF / TV Justiça / judicial deliberation

HIIIIIIIIIIIIIIIIIIIIIIIIIIIIIIIIII

\begin{abstract}
Several authors have been speculating about the influence of "TV Justiça" in the decision-making process of STF. In the same direction, the court's own judges have attributed certain effects on the argumentative behavior of the court to the telecasting of the court's plenary sessions. In general, there is a high degree of agreement with propositions such as: "Beginning with the session's telecasting, judge's opinions became longer" and "Excessive exposure of the debate cause it to be less candid". The purpose of this paper is to present new empirical evidence about the effects of "TV Justiça" in order to evaluate previous statements about it in the literature. At the most basic level, we need to know if "TV Justiça" have or haven't made a difference over the judge's deliberative behavior. Our results indicate that there is, in fact, a relationship between plenary session's telecasting and an increase in the decision's length in pages. In a similar way, telecasting seems to have increased the extension of the oral debates they engage in among themselves. Finally, analysis involving linear regression models indicates that the results holds even when controlling for other factors that seem to have effects on these variables.
\end{abstract}




\section{Introdução}

O debate sobre os efeitos da transmissão das sessões plenárias do STF pela TV justiça sobre o comportamento do tribunal tem gerado amplo interesse. Artigos acadêmicos (Da Silva, 2013; Arguelhes, Hartmann \& Rosevear, no prelo) e declarações dos próprios ministros ${ }^{8}$ especulam sobre a influência que o televisionamento das sessões tem sobre diversos fatores: tamanho dos votos proferidos, extensão do debate e grau de coesão do tribunal.

Deste debate, alguns truísmos surgiram, sem que, porém, tenha se realizado uma investigação empírica rigorosa de sua veracidade. Em particular, estamos preocupados com afirmações do tipo: "O tamanho dos votos proferidos pelos ministros aumentou a partir da TV justiça". Virgílio Afonso da Silva (2013), por exemplo, atribui consequências normativamente indesejáveis a partir dessa prática.

Pretendemos, portanto, investigar empiricamente essas afirmações e conjecturas. Será que de fato houve um aumento no tamanho das decisões do STF que possa ser atribuído à TV justiça? Se sim, qual é o tamanho deste aumento? De maneira mais importante, será que a TV justiça realmente causou alterações drásticas na forma como os ministros deliberam? Se esse for o caso, será que podemos afirmar que isso é, de fato, normativamente indesejável, a partir da forma e tamanho mensurável dessa mudança?

Para responder a essas perguntas, realizaremos um breve levantamento do debate sobre o televisionamento das sessões de órgãos judiciários de cúpula (I), exporemos nossa metodologia de pesquisa (II) e, por fim, discutiremos os resultados colhidos e quais suas consequências para o debate normativo sobre a TV justiça.

\section{0 debate sobre o televisionamento}

No Brasil e em diversos outros países, o televisionamento e a publicidade das deliberações judiciais, de uma forma ou de outra, provocam intenso debate.

8 Conferir, por exemplo, a entrevista do Ministro Nelson Jobim para o Projeto História Oral do Supremo Tribunal Federal realizado pela Fundação Getúlio Vargas.
Uma maneira de expor esse debate é agrupar os argumentos apresentados em dois grupos: a) argumentos pró-televisionamento/publicidade e b) argumentos contra o televisionamento/publicidade. Ambos partem do pressuposto não verificado de que o televisionamento/publicidade das práticas argumentativas e deliberativas dos tribunais de fato alteram de alguma maneira o seu comportamento.9 Nesta seção, faremos uma pequena revisão dos dois grupos de argumentos para, posteriormente, e, à luz de nossa pesquisa empírica, discutirmos brevemente seu mérito e estratégias que nos permitam sair do impasse em que o debate se encontra.

\subsection{Argumentos pró-televisionamento/ publicidade}

$\mathrm{O}$ argumento básico a favor do televisionamento das sessões deliberativas de tribunais está ligado à ideia de legitimidade democrática. Tribunais de cúpula, na maior parte do mundo, não são compostos por juízes eleitos. Sua legitimidade democrática, portanto, parece advir de sua argumentação, das razões que o tribunal fornece para sustentar as suas decisões e da repercussão que essa argumentação tem na sociedade. ${ }^{10}$

Se esse é o caso, parece que, de fato, os efeitos esperados da transmissão televisiva dos debates judiciais seriam normativamente desejáveis. Afinal, transmitir a deliberação judicial permitiria que os cidadãos fiscalizassem com mais afinco como uma parte extremamente poderosa do governo funciona. Isso, por sua vez, tendo em vista o modo de seleção dos juízes das cortes de cúpula em países como o Brasil e os Estados Unidos, permitiria que a população votasse de forma mais informada. Por exemplo, se um presidente indica uma boa parte dos juízes do órgão judiciário de cúpula e a população discorda da forma como esses juízes decidem, parece natural que ela utilize o poder de seu voto para impedir a reeleição daquele

9 Nesse sentido, Carter (2012).

10 Ver, por exemplo, Dworkin, 2005; Vojvodic, Machado \& Cardoso, 2009: "[o potencial democrático do STF advém de] Argumentos que talvez tenham sido levantados na esfera pública, por meio do debate promovido pelo trâmite do caso no STF", p. 38; Da Silva, 2013: "One of [the sources of court's legitimacy] is namely the quality of deliberation within the courts", p. 557. De maneira similar, a CRFB/88 dispõe, em seu art. 93, IX que "todos os julgamentos dos órgãos do Poder Judiciário serão públicos, e fundamentadas todas as decisões, sob pena de nulidade [...]". 
presidente ou a eleição de outro presidente daquele partido (Goldfarb, 1998).

Se é verdade que a imprensa, através da discussão pública dos atos do governo, desempenha a função de prevenir abusos de poder e é um meio constitucionalmente eleito para responsabilizar o governo perante a população, parece natural estender o raciocínio e defender a transmissão da deliberação judicial (RonNell, 2012). Isso é especialmente verdadeiro quando imaginamos que as cortes discutem e decidem algumas das questões politicamente mais sensíveis de nossas comunidades (Fragale Filho, 2012).

No Brasil, em particular, alguns ministros do STF têm demonstrado entusiasmo com o potencial da TV Justiça em linhas similares, enfatizando o papel que a transmissão das sessões tem em garantir transparência e legitimidade à cúpula do poder judiciário. Um bom exemplo é o pronunciamento do Ministro Celso de Mello celebrando o $10^{\circ}$ aniversário da TV justiça:

Na realidade, a TV Justiça constitui valioso instrumento a serviço do interesse público, eis que, ao aproximar os cidadãos dos magistrados e Tribunais deste País, em decorrência do intenso grau de visibilidade que confere ao sistema de administração da justiça, culmina por atribuir maior coeficiente de legitimidade democrática ao funcionamento da instituição judiciária. ${ }^{11}$

A esses argumentos, Chemerinsky soma ainda considerações sobre a função comunicativa da Corte. Se, no caso americano, poucas pessoas leem as decisões que ela publica, parece que a transmissão televisiva das sessões de julgamento implicaria, no mínimo, em um potencial comunicativo maior, tornando as decisões mais acessíveis à população em geral (Chemerinsky, 2012).

Em resumo, defensores do televisionamento/publicidade da deliberação judicial afirmam que essas práticas podem aumentar a legitimação democrática da atuação das cortes e tornar o direito mais claro para a população em geral.

11 Disponível em: <http://www.stf.jus.br/arquivo/cms/noticianoticiastf/anexo/mcm10anostv.pdf>. Acesso em: 03 ago. 2016.

\subsection{Argumentos contra o televisionamento/ publicidade}

O cerne dos argumentos contra o televisionamento/publicidade das deliberações judiciais é a ideia de que a qualidade e franqueza dos debates entre os ministros é maior quando não há o constante escrutínio público de sua deliberação. Virgílio Afonso da Silva, por exemplo, argumenta que "deliberar em público claramente reduz a abertura do participante a contra-argumentos e, acima de tudo, a sua suscetibilidade a mudar de opinião" (Da Silva, 2013). Fatores como a preocupação com a imagem pública dos juízes individuais e da corte como um todo, bem como o medo de abertamente discutir questões moralmente polêmicas tornariam a deliberação menos franca em fóruns abertos, tornando tal desenho institucional indesejável para o tipo de decisão que cortes de cúpula geralmente tomam (Chambers, 2004).

Reforçando as conclusões do prof. Virgílio Afonso da Silva, Mitchel Lasser, parafraseando Michael Lawrence, comenta que, nos Estados Unidos:

[...] most regulatory officials 'believed that the presence of the press and public under open meeting statues subtly inhibit the free Exchange of ideas and opinions'. [...] The [sunshine] Act has thus 'led to diminished collegiality and increased inhibitions among agency decision makers' (Lasser, 2013).

À extrema abertura advinda das "sunshine laws",12 Lasser contrapõe a Corte de Cassação (um dos órgãos de cúpula do judiciário francês), que delibera de maneira fechada e publica apenas decisões curtas e silogísticas, que não permitem que o público tenha acesso direto ao raciocínio da corte. Essa característica da Corte de Cassação francesa, muitas vezes criticada (Lasser, 2013, pp. 328-329), é identificada pelo autor como uma vantagem com relação à abertura argumentativa americana. Os juízes franceses, blindados

12 A referência principal de Lasser é uma lei de 1976 conhecida como o "Government in the sunhsine act". Por mais que essa lei atribua um certo ônus argumentativo aos órgãos do governo federal americano, não há nada nesta lei que se aproxime sequer remotamente do tipo de abertura proporcionado pela TV Justiça, de maneira que o argumento de Lasser contra o sistema judicial e administrativo americano vale de maneira fortalecida contra o sistema brasileiro. 
da opinião pública por suas práticas deliberativas, possuem mais liberdade, podem argumentar com mais franqueza e, por consequência, tomam decisões melhores do que a de seus colegas americanos.

Outros efeitos negativos costumam ser atribuídos à transmissão, em particular quanto ao aumento da extensão dos votos que cada ministro lê durante a sessão de julgamento, nesse sentido, o ex-Ministro Nelson Jobim:

E aí você teve uma mudança, uma mudança muito forte no comportamento dentro do plenário. Então aquilo que era voto de acordo começou a diminuir muito, que aí começaram, que aí os votos começaram a se espichar, começaram a se alongar. O negócio... não terminava nunca aquilo. Eram votos longos. Por quê? Porque estavam sendo gravados. ${ }^{13}$

De maneira similar, Felipe de Melo Fonte (2013) observa que os acórdãos, em ações diretas de inconstitucionalidade, cresceram 58,7\% de tamanho. Esse aumento pode ser valorado negativamente. Decisões mais curtas são mais fáceis de ler ou de assistir. Como elas demandam menos tempo e atenção, é provável que um número maior de pessoas seja capaz de acessar as razões do tribunal em decisões curtas do que em decisões longas.14 Se a TV Justiça cria uma pressão institucional no sentido de aumentar o tamanho das decisões, é de se esperar que menos pessoas leiam as decisões ou assistam às sessões de julgamento.

Isso é um problema para os argumentos pró-televisionamento porque, como vimos, esses argumentos tendem a depender do aumento da legitimidade do tribunal a partir da maior divulgação de seus julgados. Caso os julgados não sejam de fato lidos ou assistidos porque são muito longos, o argumento não funciona para defender a TV Justiça e outros meios análogos de exposição da deliberação judicial.

13 Entrevista concedida ao projeto História Oral do Supremo Tribunal Federal, da Fundação Getúlio Vargas.

14 Ainda assim é possível defender que decisões mais longas são melhores: podemos dizer que elas consideram mais argumentos, são mais metódicas, mais exaustivas, etc.

\section{Hipóteses}

O debate acima evidencia a existência de importantes considerações normativas com relação à publicidade da deliberação judicial. A maioria desses argumentos, porém, parte da premissa de que o televisionamento das sessões de julgamento ou outras formas de publicidade da atividade judicial altera de alguma forma o comportamento dos julgadores. Essa premissa não foi empiricamente investigada de maneira satisfatória no âmbito do STF. Ainda que estudos anteriores apontem alterações no comportamento dos ministros no caso específico das ADIs (Fonte, 2013), esse fenômeno pode não ser generalizável para o restante das ações julgadas pelo tribunal. Logo, qualquer análise empírica dos efeitos da TV Justiça deve se iniciar testando se houve de fato alguma influência desta sobre as práticas decisórias do tribunal. Apenas depois de responder afirmativamente a essa pergunta é que podemos investigar em qual direção e com que magnitude essa influência se dá.

Portanto, nossa hipótese é que a TV Justiça influencia o comportamento dos ministros. Caso esta hipótese seja confirmada, queremos saber em qual direção ocorre essa influência, para então discutirmos alguns dos argumentos normativos supra.

\section{$4 \quad$ Método}

\subsection{Dados}

Adotamos metodologia de pesquisa empírica, com técnica quantitativa. Os dados foram levantados usando uma das bases de dados do projeto Supremo em Números. Trata-se de projeto de pesquisa do Centro de Justiça e Sociedade (CJUS) da Escola de Direito da Fundação Getúlio Vargas (FGV), no Rio de Janeiro. Desde 2010, o projeto realiza macro análises dos processos que chegaram ao Supremo a partir da Constituição de $1988 .{ }^{15}$ Mais recentemente, foram iniciadas pesquisas também com bases de dados do Superior Tribunal de Justiça, do Tribunal de Justiça do Rio Grande do Sul e do Tribunal de Justiça do Rio de Janeiro.

15 Ver, por exemplo, Falcão \& Werneck, 2011; Falcão et al, 2013; Falcão, Hartmann \& Chaves, 2014; Falcão, Moraes \& Hartmann, 2016. 
Pesquisas como esta, envolvendo grandes data sets, têm permitido aos juristas analisar, de maneira muito mais minuciosa, decisões judiciais (Diamond \& Mueller, 2010). Nesse contexto, a disponibilidade de equipamento computacional, software e suporte técnico desempenha um papel-chave na viabilização de estudos empíricos pelos pesquisadores do Direito nos Estados Unidos (Epstein \& King, 2003). A mesma situação existe no Brasil onde faculdades de Direito estão começando a adaptar-se a essa realidade, tornando o acesso a tal instrumento um elemento ainda mais importante (Veronese, 2007). Os dados que subsidiam esse artigo, bem como a diversificada produção do projeto Supremo em Números, são possíveis somente em razão do uso de uma ferramenta tecnológica potente. ${ }^{16} \mathrm{O}$ novo movimento de estudos empíricos (Yanow \& Schwartz-Shea, 2006) no Direito, no qual o presente estudo se insere, sempre se distinguiu do realismo jurídico e da sociologia jurídica em que as pesquisas são preponderantemente quantitativas, e não qualitativas (Suchman \& Mertz, 2010).

A base de dados utilizada para gerar uma amostra das decisões colegiadas está em formato SQL e contém todos os processos que ingressaram no Supremo Tribunal Federal entre 1988 e 2013. Além das informações básicas sobre os processos e as partes, fazem parte da base meta-dados sobre os processos como o assunto jurídico, o órgão judicial responsável, a turma e o órgão judicial de origem, entre outras. Os andamentos abrangem informações sobre datas e decisões tomadas durante os processos, datas de distribuição dos processos, datas de conclusão ao relator do processo, trânsito em julgado e similares.

Utilizamo-nos de uma amostra aleatória estratificada em estágio único contendo 2.213 observações da

16 Há várias décadas os pesquisadores já haviam identificado os ganhos do uso da informática na pesquisa sobre comportamento judicial. Ver, por exemplo, Schubert (2008): “The computer is a useful instrument in research in behavioral jurisprudence because (1) it facilitates inquiry by reducing time costs, thus freeing the investigator for routine operations (...) (2) it makes feasible many types of inquiry that could not have been undertaken heretofore (...) and (3) it provides, increasingly, better data (in the sense of empirical observations that have been transformed by the researcher into quantified units suitable for measurement manipulations) by making feasible a greatly expanded repertoire of alternative modes of analysis", p. 60. base de dados do Supremo em Números. Consideramos apenas decisões colegiadas entre 1992 e 2013, o que significa que podemos analisar aproximadamente 10 anos de decisões anteriores à TV Justiça, implementada em 2002 e 10 anos de decisões após a implementação desta.

Embora seja sempre desejável realizar análises que levam em consideração a base de dados inteira, contendo todas as decisões proferidas pelo STF durante um determinado período, isso nem sempre é possível. A análise do comportamento institucional do STF antes e depois da TV Justiça exigiu a mensuração de certas variáveis que não se encontravam na base e que precisaram ser codificadas manualmente. ${ }^{17}$ Esse dataset foi produzido por Arguelles, Hartmann \& Rosevear (no prelo) e procedemos à codificação de variáveis adicionais nas mesmas decisões. Todas as análises apresentadas levam em conta a estratificação da amostra. Como a TV justiça cobre apenas as sessões plenárias, consideramos apenas um subconjunto do dataset, contendo 733 observações de decisões proferidas pelo plenário.

\subsection{Variáveis}

Todas as análises abaixo se dão com base nas seguintes variáveis:

1. Extensão dos votos

2. Número de votos efetivos

3. Número total de votos proferidos

4. Proporção de votos efetivos

5. Extensão do debate

6. Número de ministros presentes no debate

7. Índice de complexidade

8. Taxa de coesão

9. Debate agregado

10. Extensão agregada

11. Televisionamento

12. Vista

13. Ano da decisão

As variáveis 1-6 foram codificadas manualmente pelos autores. Cada codificador trabalhou em quatro batches. Cada batch continha 100 processos, haven-

17 Ver a discussão infra para detalhes sobre a codificação de cada variável. 
do sobreposição de 5 a 15\%, a depender do batch. 0 "overlap" de processos iguais em cada planilha foi feito para verificar se havia discrepâncias na forma de preenchimento de cada um dos coders, o que não ocorreu nem para variáveis discretas, ${ }^{18}$ nem para variáveis contínuas. ${ }^{19}$

Foram estabelecidos alguns critérios para a codificação das decisões. O primeiro foi que somente seriam considerados os votos proferidos na sessão na qual tivesse sido tomada a decisão final (terminativa) de um dado processo. Desse modo, em processos onde mais de uma sessão foi necessária para a conclusão, as sessões anteriores à última não tiveram seus votos computados neste trabalho.

Ao medirmos a extensão dos votos de cada ministro (1), tentamos produzir uma variável que fosse útil, medindo a extensão "real" das decisões. Se um ministro se limita a acompanhar o relator, ou o voto de algum outro ministro, não parece que houve, de fato, um acréscimo substantivo à decisão. Para controlar esse fator, estabelecemos o seguinte critério: se o voto tivesse menos de dez linhas, codificamos o tamanho do voto como zero. Se, porém, o voto tivesse mais de dez linhas, cada página seria contada para a variável, independentemente do seu tamanho ou conteúdo. Assim, as páginas que compõem o relatório, por exemplo, contam para nosso cálculo. A mesma lógica se aplica ao cálculo da extensão do debate em páginas (5): debates com menos de dez linhas foram codificados como possuindo extensão 0 e cada página subsequente foi contada independente de seu tamanho em termos de linhas ou caracteres.

Com frequência, votos com menos de dez linhas são aqueles nos quais os ministros se limitam a afirmar que seguem o relator, o que nos permitiu criar uma métrica que indica, aproximadamente, o número de votos concorrentes ou dissidentes que de fato foram proferidos em uma determinada sessão (2), contando o número de votos cuja extensão em (1) seja maior que 0 . Esses votos serão chamados de "votos efetivos".

18 Para todas as variáveis, kappa de Fleiss $=1(p<0.0001)$. 19 A soma de todas as variáveis contínuas de cada codificador para os batches com overlap foi testada através de um teste de correlação intraclasse $=0,991(p<0.0001)$.
Criamos também a variável 3 , que conta quantos votos foram proferidos em uma determinada sessão, independentemente do número de linhas ou páginas desta seção. Para tal, contamos o número de votos com extensão maior ou igual a zero.

A variável 4 foi gerada a partir das variáveis anteriores, consistindo na divisão do número de votos efetivos (2) pelo nú mero total de votos (3).

Para medirmos a percepção de complexidade das classes processuais (7), foram enviados 34 (trinta e quatro) e-mails para profissionais da área do Direito relacionados com Direito Constitucional e com o estudo do Supremo Tribunal Federal. Esses profissionais são de diversas instituições, como UERJ, FGV Direito SP, PUC, USP, UNB, dentre outras. Optamos por não incluir professores da FGV Direito Rio, a fim de evitar que um possível viés influenciasse os resultados.

Os e-mails enviados pediam para que os professores graduassem 27 classes processuais de acordo com a sua complexidade, numerando-as de 1 a 5 , sendo 1 a menor complexidade possível e 5 a maior. No corpo do e-mail sugerimos alguns critérios, não cumulativos ou excludentes, e sem prejuízo de outros que fossem entendidos como pertinentes. As sugestões foram: dificuldade jurídica do processo, dificuldade política, exposição à opinião pública, impacto do resultado, duração do tipo de processo. A partir das 14 (quatorze) respostas ${ }^{20}$ que obtivemos, fizemos a média dos valores atribuídos pelos professores para, dessa forma, atribuirmos uma média de complexidade para cada classe processual. O resultado deste cálculo é o índice de complexidade do processo (7).

Novamente na esteira de Arguelhes, Hartmann \& Rosevear (no prelo), calculamos a taxa de dissenso (8) como a diferença entre votos concorrentes e votos dissidentes dividida pelo número de votos proferidos em cada processo. Assim, o resultado varia entre 0 (houve empate) e 1 (decisão unânime).

20 Professores que nos responderam: Antonio Cabral, Ingo Sarlet, Dimitri Dimoulis, Fábio Leite, Jose Vicente, Carlos Bolonha, Maria Tereza Sadez, Marcelo Novelino, Ana Paula de Barcellos, Daniel Sarmento, Jane Reis, Eloisa Machado, Roberto Baptista e Margarida Lacombe. 


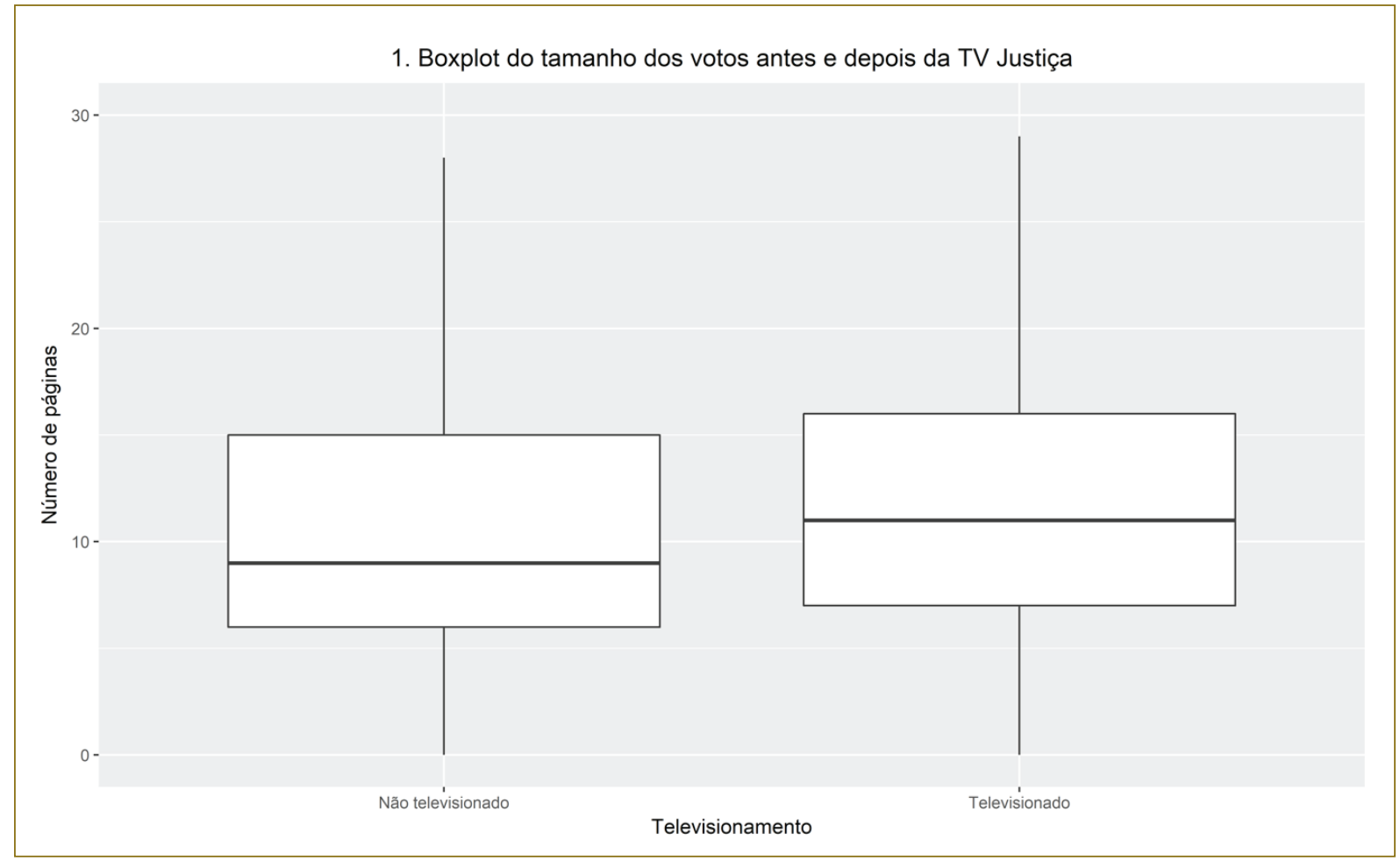

Durante a análise dos dados colhidos, percebemos que as variáveis (5) número de ministros em debate e (6) extensão do debate em laudas apresentavam alta correlação ( $r$ de Pearson $=0.8, p<0.0001$ ). Portanto, para que tivéssemos uma métrica mais confiável dos debates, realizamos a maior parte das análises considerando uma versão agregada das duas variáveis, que denominamos, simplesmente, "Debate agregado", obtida a partir da multiplicação das duas variáveis. Para algumas análises, porém, utilizamos apenas a variável (6), por facilidade de exposição.

O mesmo ocorre com relação às variáveis (1) e (4) ( $r$ de Pearson $=0.39, p<0.0001)$. Novamente, pelos mesmos motivos, criamos uma variável que agrega as duas, obtida a partir da multiplicação de ambas. ${ }^{21}$

21 No caso das duas variáveis combinadas, agregamos de duas formas distintas e estamos reportando apenas a versão mais simples. No segundo caso, para validar a opção pela agregação, realizamos a junção das variáveis através de um método estatístico chamado PCA (principal componente analysis). Os resultados não foram significativamente diferentes. Da mesma forma, todos os resultados se mantém mais ou menos semelhantes em termos das inferências que permitem mesmo como variamos a análise. Por exemplo, se consideramos apenas a variável (a), ao invés da variável agregada, ainda assim os resultados se mantém significativamente seme-
Finalmente, as variáveis 11-13 estavam disponíveis na base de dados do Supremo em Números, representando, respectivamente se a sessão foi ou não televisionada (11), se houve ou não pedido de vista por parte de algum dos ministros (12) e o ano em que foi proferida a decisão (13).

\section{Resultados}

\subsection{As decisões e os debates aumentaram após a TV Justiça?}

Em um primeiro momento, testamos a diferença das médias da soma dos votos entre os processos proferidos pelo plenário do STF antes e depois da TV justiça (gráfico 1). Um t-test que levava em consideração a estratificação da amostra indicou uma diferença significativa entre as médias $(p<0,05)$. Nos processos julgados em sessões plenárias sem transmissão pela TV justiça, a média da soma dos votos é de 13,23 páginas. Naqueles onde houve transmissão, a média é de 15,55 páginas. 0 mesmo é verdadeiro para a extensão do de-

Ihantes. Diversas análises alternativas estão disponíveis nos materiais suplementares. 
bate ( $p<0,0001)$. Sem o televisionamento, a média da extensão do debate entre ministros era de 0,4 páginas, contra 1,58 páginas nas sessões televisionadas. ${ }^{22}$

\section{2 É possível atribuir essa diferença à TV Justiça?}

Apesar desses resultados indicarem que a TV Justiça influenciou o comportamento do STF, é possível argumentar que esse não é o caso. Afinal, não é incomum afirmar que o STF tem decidido processos mais importantes, polêmicos e disputados, ${ }^{23}$ o que poderia oferecer uma explicação concorrente para os aumentos observados na média de extensão das decisões em termos de votos e debates.

Para controlar esses fatores, elegemos algumas variáveis que parecem indicar o grau de dificuldade ou importância relativa de um processo. Assim, inicialmente, escolhemos controlar a influência que a transmissão televisiva tem sobre o número de páginas da decisão através das seguintes variáveis: existência ou inexistência de pedido de vista (12), taxa de coesão da decisão (8), índice de complexidade (7) e votos proferidos (3). Dessas quatro variáveis, as três primeiras presumivelmente representam maneiras indiretas de se testar o grau de dificuldade de um determinado processo, enquanto a última (3) funciona como um controle para a eventual ausência de ministros. Elas foram incluídas como preditoras em um modelo de regressão linear múltipla que buscava prever uma de duas variáveis dependentes: (1) extensão em páginas da soma dos votos ou (5) extensão em páginas do debate entre os ministros. Adicionalmente, cada um dos dois modelos incluía ainda, como um preditor adicio-

22 Ambos os testes, na verdade, violam uma das presunções do t-test porque os dados não são normalmente distribuídos. Aplicando o teste de soma de rankings de Wilcox com correção de continuidade, porém, ambos permanecem apontando diferenças estatisticamente significativas entre o tamanho das variáveis em ambas populações (ps < 0,05). Os testes reportados, conforme observado anteriormente, apresentam correções com pesos para os estratos da amostra, usando "bootstraped standard error estimation". Ver Paseck, 2016.

23 "Tudo isso nos dá a impressão de que o STF tem se deparado cada vez mais com 'casos difíceis' - interrupção da gestação de fetos anencéfalos, pesquisas com células-tronco, demarcação de terras indígenas, união homoafetiva, proibição de nepotismo - e conquistou um espaço diário e aparentemente definitivo nos jornais, tornando-se um ator político relevante" (Vojvodic, Machado \& Cardoso, 2009, p. 22). nal, a variável dependente prevista pelo outro modelo. Assim, (5) funcionava como um dos preditores de (1) e vice-versa. Em ambos modelos, naturalmente, a última variável independente era a que indicava a presença de televisionamento (11), objeto do teste.

Mesmo levando em conta todos esses fatores, o televisionamento das sessões ainda exerceu uma influência significativa sobre a variável dependente da extensão do debate (modelo $I I, r^{2}$ ajustado $=0,28$ ), causando um aumento de 1,79 páginas. No caso da extensão total dos votos, a influência da variável que indicava o televisionamento não foi significativo (modelo I, $\mathrm{r}^{2}$ ajustado = 0,29), o que pode ser explicado pela alta influência da extensão dos debates, o que sugere uma mediação dos efeitos.

\section{3 É possível que isso seja um mero efeito do tempo?}

Por fim, notamos uma correlação ( $r$ de Pearson $=0$, $25, p<0,0001$ ) entre a extensão do debate (5) e o ano da decisão (13). Como o dataset é composto por processos julgados entre 1992 e 2013, é natural que exista, como existe, uma correlação significativa ( $r$ de Pearson $=0,82, p<0,0001$ ) entre a variável que registra o ano da decisão (13) e aquela que registra a presença ou ausência de transmissão pela TV Justiça (11). Afinal, até 2002, nenhum julgamento do plenário era transmitido e, após 2002, todos são transmitidos. Portanto, imaginamos ser necessário controlar de alguma forma o efeito que o tempo tem, em particular sobre a variável dependente extensão do debate (5). Infelizmente, a forte colinearidade (número de condição $=1510$ ) existente entre essas duas variáveis impede que ambas funcionem no mesmo modelo sem causar sérios problemas na precisão dos coeficientes da regressão linear (Callaghan \& Chen, 2008). Portanto, buscamos uma estratégia alternativa para testar a influência relativa dos dois fatores.

Partimos da hipótese de que os mesmos fatores, que funcionam como medidas indiretas de importância e dificuldade relativa dos processos, deveriam explicar uma porcentagem maior da variação nas variáveis agregadas (9 e 10) após 2002, com a transmissão das sessões de julgamento do plenário, do que antes, quando não havia tais transmissões. A ideia é que processos mais importantes/difíceis recebem ainda 
Tabela 1.

\begin{tabular}{|c|c|c|c|c|}
\hline & Modelo $7 a$ & Modelo 7b & Modelo 8a & Modelo 8b \\
\hline & $\begin{array}{l}F(5,2207)=105.5 \\
R 2=.19\end{array}$ & $\begin{array}{l}F(8,2204)=94.6 \\
R 2=.26\end{array}$ & $\begin{array}{l}F(5,2207)=43.09 \\
R 2=.09\end{array}$ & $\begin{array}{l}F(8,2204)=50.97 \\
R 2=.16\end{array}$ \\
\hline \multicolumn{5}{|l|}{ Órgão } \\
\hline 1 & $-.03(.3)$ & $-.001(.29)$ & $-.008(.04)$ & $.05(.06)$ \\
\hline 2 & $8.45(.63)^{\star \star \star}$ & $7.01(.63)^{\star \star \star}$ & $.4(.13)^{\star \star}$ & $.04(.13)$ \\
\hline Período & $1.8(.44)$ & $1.95(.43)^{\star \star \star}$ & $.02(.09)$ & $.05(.09)$ \\
\hline \multicolumn{5}{|c|}{ Órgão\#Período } \\
\hline 11 & $1.57(0.7)^{*}$ & $-0.44(.69)$ & $.8(.15)^{\star \star \star}$ & $-.42(.14)^{\star \star}$ \\
\hline 21 & $.87(0.36)$ & $.73(.92)$ & $1.22(.2)^{\star \star \star}$ & $1.19(.19)^{\star \star \star}$ \\
\hline Complx & & $-.16(.27)$ & & $-.03(.06)$ \\
\hline Coesão & & $-14.47(1.07)^{\star \star \star}$ & & $-2.7(.22)^{\star \star \star}$ \\
\hline Vista & & $-1.78(1)$ & & $.36(.21)$ \\
\hline Constante & $4.67(.21)^{\star \star \star}$ & $19.33(1.4)^{\star \star \star}$ & $.008(.04)$ & $2.80(.45)^{\star \star \star}$ \\
\hline
\end{tabular}

mais atenção e geram uma pressão ainda maior para que os ministros ofereçam uma justificativa exaustiva (aumento na extensão média dos votos em números de página (1) e no percentual de votos efetivos (4), agregados em (9) para suas decisões. Alternativamente, essa maior publicidade também pode causar maior discórdia entre os ministros (aumentando a extensão dos debates (5) e o número de ministros engajados neles (6), agregados em (10) quando sua deliberação está sendo transmitida pela televisão.

Essa hipótese foi testada através da comparação do poder preditivo de modelos de regressão linear múltipla que levavam em conta o período de 1992 até 2001 e modelos que levavam em conta as decisões tomadas de 2003 em diante. Para cada uma das variáveis dependentes, portanto, foi feita a comparação entre o poder preditivo de dois modelos diferentes: um referente ao período anterior à transmissão das sessões pela TV Justiça e outro referente ao período posterior. Em todos os casos, as variáveis independentes do modelo foram as mesmas utilizadas anteriormente, a saber, existência ou inexistência de pedido de vista (12), taxa de coesão da decisão (8), índice de complexidade (7), votos proferidos (3) e a variável dependente do outro modelo (extensão agregada prevê debate agregado e vice-versa).

Os resultados confirmaram a hipótese. Tanto no caso do debate agregado (9) $\left(r^{2}\right.$ ajustado anterior $=0,103$, no modelo IIIb, contra $r^{2}$ ajustado posterior $=0,359$, no modelo IVb) quanto no caso da extensão agregada $\left(r^{2}\right.$ ajustado anterior $=0,117$, no modelo $\mathrm{Vb}$, contra $r^{2}$ ajustado posterior $=0,196$, no modelo VIb), o poder preditivo do modelo foi consideravelmente maior no período posterior do que no período anterior. ${ }^{24}$

\subsection{Modelos agregados}

Finalmente, para analisar a influência da TV justiça sobre a extensão dos votos (1; modelos 7a e 7b) e a extensão dos debates ( 5 ; modelos $8 \mathrm{a}$ e $8 \mathrm{~b}$ ), estimamos modelos de regressão com o órgão ( $0: 2^{\mathrm{a}}$ Turma, 1: $1^{\text {a }}$ Turma e 2: Plenário) e período (0: antes de 2002 e 1: depois de 2002), como fatores ortogonais, com (modelos 1b e 2b) e sem (modelos 1a e 2a) vista, (12), complexidade (7) e coesão (8) como covariantes. ${ }^{25}$ Já que apenas as sessões depois de 2002 foram televisionadas, a interação entre o órgão julgador e o período, depois de controlar para os efeitos principais de órgão e período, fornecem um teste para o papel da TV Justiça sobre as variáveis dependentes.

Os gráficos 1 e 2 mostram as margens da matriz da interação entre o órgão e o período (em primeiro lugar: extensão dos votos em páginas; em segundo lugar: extensão do debate em páginas). A inclinação maior do plenário (linha azul) entre os períodos sugere que

24 Os resultados se mantêm quando analisamos cada uma das variáveis dependentes desagregadas, bem como quando as avaliamos conjugadas com outra técnica, como se pode depreender da leitura dos anexos, onde os modelos alternativos são identificados como modelos Ib-VIb.

250 termo de interseção (intercept) é definido, para os fins dos modelos supra, como o primeiro nível das variáveis independentes. Assim, os coeficientes reportados dizem respeito ao tamanho do efeito que órgão e período têm com relação ao período anterior a 2002 e com relação à $2^{\mathrm{a}}$ Turma. 
Gráfico 1.

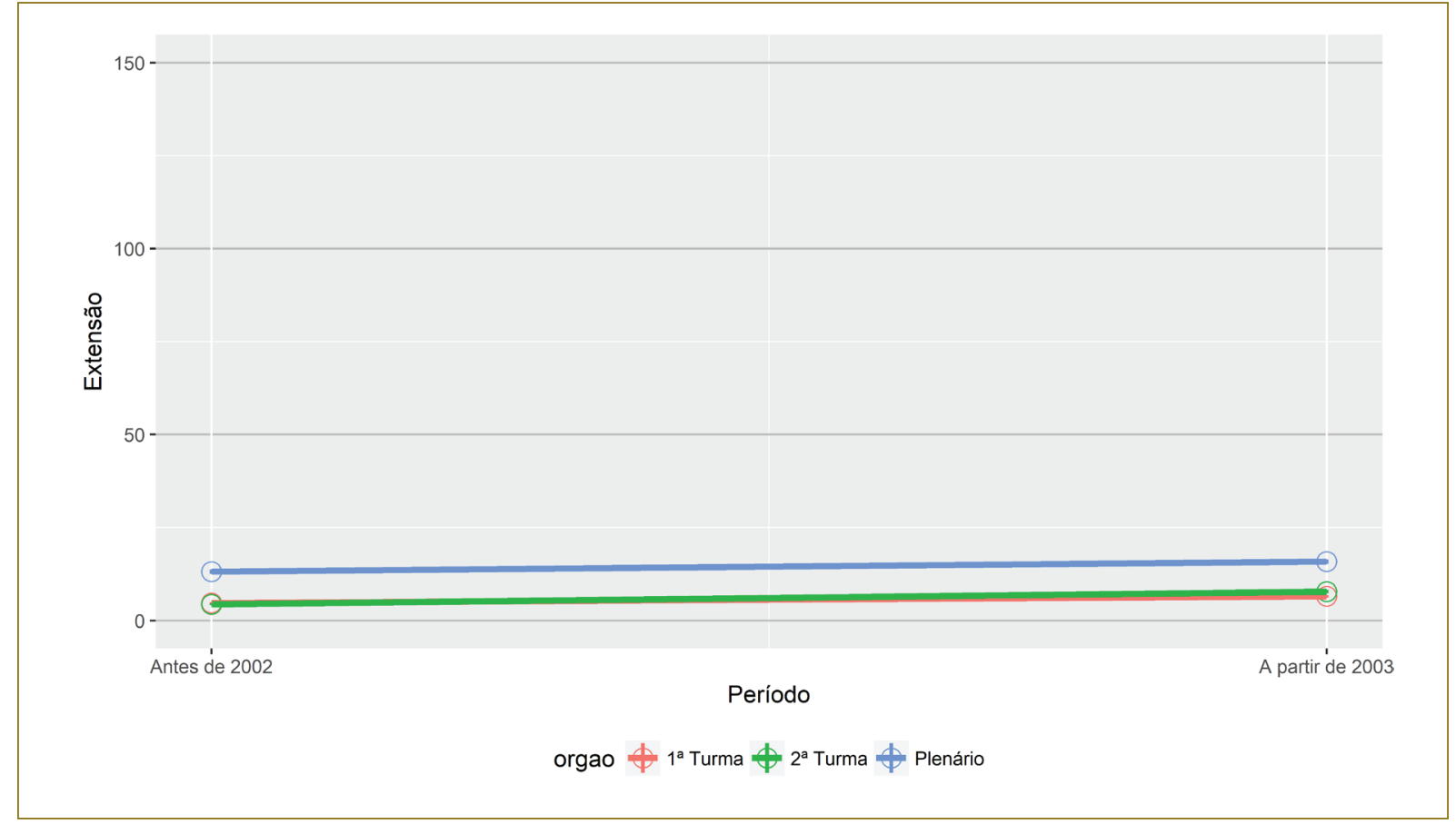

Gráfico 2.

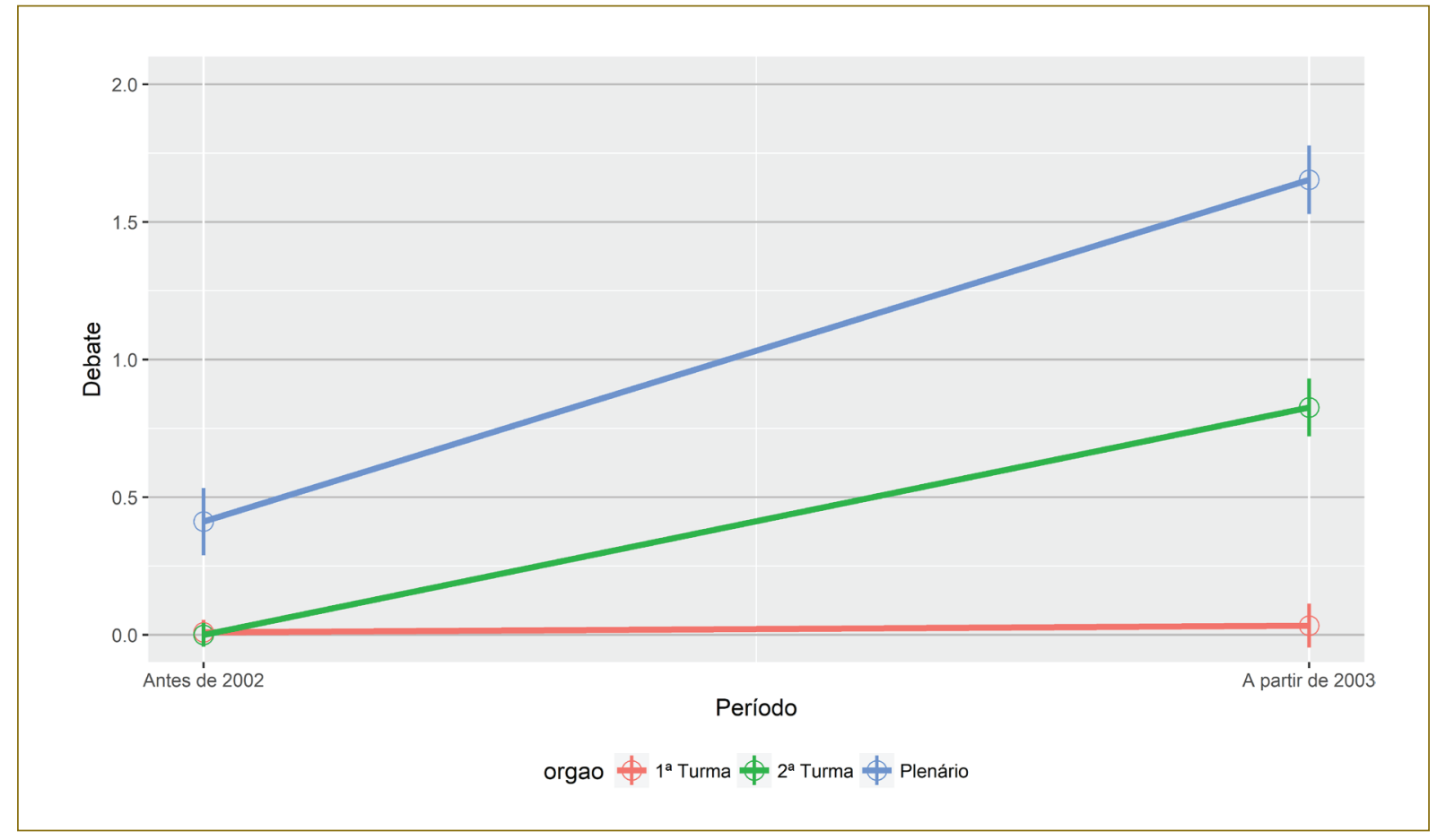


o efeito da TV Justiça é consideravelmente maior do que os efeitos gerais de órgão (o plenário geralmente tem valores maiores) e do período (valores geralmente maiores a partir de 2002) no caso da extensão do debate, mas não há diferença significativa com relação à extensão dos votos. Isso significa que, mesmo controlando para os fatores supra e reconhecendo sua influência sobre as variáveis dependentes, ainda subsiste um efeito significativo atribuível diretamente ao televisionamento das sessões de julgamento no caso dos debates. Isso é consistente com os modelos apresentados acima, ressalvada a possibilidade de um efeito indireto do televisionamento das sessões na extensão dos votos. Afinal, sabemos que há uma correlação estatisticamente significativa entre a extensão dos debates e a extensão dos votos - o que pode ser observado nos modelos I e II. Se há, também, uma relação estatisticamente significativa entre televisionamento das sessões e mais debates - como comprovam todos os modelos que usamos para investigar o tema - é possível que exista um efeito indireto do televisionamento sobre a extensão dos votos.

\section{Conclusão}

As análises acima referendam parcialmente a ideia de que o tamanho das decisões, em particular dos votos que cada ministro profere, aumentou em função da TV Justiça. Por outro lado, nossos dados mostram claramente que os ministros têm se engajado em debates mais extensos e isso parece ser causado pela publicidade de suas decisões. A forte relação entre o tamanho dos debates e a extensão dos votos, observada nos modelos I-II e la-Ila, pode sugerir uma relação de mediação, onde uma influência direta da TV Justiça sobre a probabilidade de haver um debate influa de maneira indireta na extensão dos votos. De toda forma, a discussão teórica que vem sendo travada sobre o televisionamento das deliberações judiciais, portanto, parece se sustentar sobre uma premissa empiricamente verificada.

Naturalmente, porém, a mera constatação de que ele trata de um fenômeno que de fato existe não nos permite inferir nada sobre o status normativo deste fenômeno. Partir da mera constatação, por exemplo, de que as decisões e debates se tornaram mais longos para concluir que, portanto, o STF é mais legíti- mo é inferir um dever ser de um ser. O mesmo pode ser dito de um juízo de mérito positivo ou negativo acerca do televisionamento extraído diretamente dos dados empíricos demonstrando uma mudança de comportamento dos ministros. Não é isso que defendemos e o objetivo desse estudo não é avaliar se o televisionamento é bom ou ruim a partir da constatação de seu impacto.

Pode ser que o STF tenha se tornado mais prolixo, mas menos honesto ou menos franco em suas deliberações; é possível que uma boa parte da população continue alienada da fundamentação oferecida pelos ministros por causa da linguagem utilizada ou por causa da excessiva duração dos debates e etc. Da mesma forma, decisões e debates mais longos podem muito bem ter tornado o tribunal mais transparente ou legítimo. Essas permanecem questões abertas, envolvendo intuições conflitantes que provavelmente não serão resolvidas pelo mero debate teórico. ${ }^{26}$

A perspectiva empírica, porém, nos permite ir além e observar algumas previsões que parecem se seguir diretamente de alguns dos argumentos do debate normativo. Será que de fato há um aumento da transparência das decisões judiciais atribuível à TV Justiça? Será que o STF se tornou mais legítimo aos olhos da população após 2002? Se conseguirmos responder a essas perguntas, estaremos mais próximos de compreender o status normativo da TV Justiça.

A TV Justiça, apesar de sua relevância teórica e das opiniões favoráveis e desfavoráveis que provoca em juristas, carece de estudos empíricos mais aprofundados. No presente artigo, fornecemos apenas um primeiro passo, consubstanciando truísmos antigos e mostrando exatamente qual o tamanho da influência da TV Justiça em alguns dos comportamentos quantificáveis dos ministros do STF.

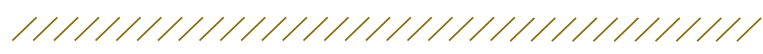

26 A ideia aqui é homóloga à defesa que Sinnot Armstrong (2008) faz da filosofia experimental. 


\section{Referências}

Arguelhes, D. W.; Hartmann, I. A. \& Rosevear, E. (no prelo). Disagreement on the Brazilian Supreme Court: An Exploratory Analysis. 10th Annual Conference on Empirical Legal Studies. Versão preliminar. Disponível em: <http://hq.ssrn.com/ViewPdf. cfm?abid=2629329>. Acesso em: 06 nov. 2015.

Black, H. C. (1957). Black's law dictionary. Kartindo. com, 1957.

Boyd, D. \& Crawford, K. (2011). Six provocations for big data. Disponível em: <http://papers.ssrn.com/ sol3/papers.cfm?abstract_id=1926431>. Acesso em: 14 jun. 2015.

Callaghan, K. \& Chen, J., 2008. Revisiting the collinear data problem: an assessment of estimator 'ill-conditioning' in linear regression. Practical Assessment, Research \& Evaluation, v. 13, n. 5. Disponível em: <http://pareonline.net/getvn. asp? $v=13 \& n=5>$. Acesso em: 09 ago. 2016.

Carter, E. L. (2012). Supreme Court Oral Argument Video: A Review of Media Effects Research and Suggestions for Study. BYU L. Rev. 1719.

Chambers, S. (2004). Behind closed doors: Publicity, secrecy, and the quality of deliberation. Journal of Political Philosophy, 12(4).

Chemerinsky, E. (2012). Failure to Communicate, A. BYU L. Rev., p. 1705. Disponível em: <http:// digitalcommons.law.byu.edu/lawreview/vol2012/ iss6/1>. Acesso em: 16 out. 2017.

Da Silva, V. A. (2013). Deciding without deliberating. International journal of constitutional law, 11(3), pp. 557-584.

Epstein, L. \& Martin, A. (2010). Quantitative approaches to empirical legal research. Disponivel em: <http:// www.oxfordhandbooks.com/view/10.1093/ oxfordhb/9780199542475.001.0001/oxfordhb-9780199542475-e-38>. Acesso em: 14 jun. 2015.

Falcão, J.; Cerdeira, P. \& Werneck, D. (2011). I Relatório supremo em números: o múltiplo supremo. Rio de Janeiro: Escola de Direito da Fundação Getúlio Vargas.

Falcão, J.; Abramovay, P.; Leal, F. \& Hartmann, I. A. (2013). II Relatório supremo em números. o supremo e a federação. Rio de Janeiro: Escola de Direito da Fundação Getúlio Vargas.

Falcão, J.; Hartmann, I. A. \& Chaves, V. P. (2014). III Relatório Supremo em Números: O Supremo e o Tem- po. Rio de Janeiro: Escola de Direito da Fundação Getúlio Vargas.

Falcão, J.; Moraes, A. \& Hartmann, I. A. (2016). IV Relatório Supremo em Números. O Supremo e o Ministério Público. Rio de Janeiro: Escola de Direito da Fundação Getúlio Vargas.

Fonte, F. M. (2013). O Supremo Tribunal Federal antese depois da TV Justiça: Rumo à sociedade aberta de telespectadores? Conjur. Disponível em: <http://s. conjur.com.br/dl/pesquisa-decisoes-colegiadas-stf.pdf>. Acesso em: 13 nov. 2015.

Fragale Filho, R. (2012). Courts on Screen. In: Aroon Manoharan and Marc Holzer (org), E-governance and civic engagement: factors and determinants of e-democracy. Hershey: IGI Global, pp. 112-116.

Gibson, J. (2010). Public images and understanding of courts. In: CANE, P.; KRITZER, H. M. (2010) The Oxford handbook of empirical legal research. Oxford: Oxford University Press.

Goldfarb, Ronald L. (1998). Television, Justice, and the Courts. New York: New York University Press.

Kassin, S. M. (1984). TV Cameras, Public Self-Consciousness, and Mock Juror Performance. Journal of Social Psychology, v. 20, Issue 4, pp. 336-349.

Lasser, M. S. -O. -L'E. (2009). Judicial deliberations: a comparative analysis of judicial transparency and legitimacy. $1^{\text {a }}$ Paperback Edition. Oxford: Oxford University Press.

Mcelroy, Lisa T. (2012). Cameras at the Supreme Court: A Rhetorical Analysis. BYU L. Rev., p. 1837.

Paseck, J. (2016). Weights: Weighting and weighted statstics. Pacote de R. Disponível em: https:// CRAN.R-project.org/package=weights. Visitado em: 18/10/2017;

Piccus, T. (1992). Demystifying the Least Understood Branch: Opening the Supreme Court to Broadcast Media. Tex. L. Rev., v. 71, p. 1053.

Ribeiro, L. (2010). Estudos empíricos no direito: questões metodológicas. In: Poder judiciário: novos olhares sobre a gestão e jurisdição. Rio de Janeiro: Editora FGV, v. 1, pp. 71-96.

Ronnell, A. J. (2012). U.S. Supreme Court Justices and Press Access. BYU L. Rev. 1791. Disponível em: $<$ http://digitalcommons.law.byu.edu/lawreview/ vol2012/iss6/4>. Acesso em: 23 out. 2015.

Scheb, J. M. \& Lyons, W. (2001). Judicial behavior and public opinion: Popular expectations regarding the factors that influence Supreme Court Decisions. 
Political Behavior, v. 23, n. 2, pp. 181-194.

Sinnot-Armstrong, W. (2008). Framing moral intuitions. In SINNOT-ARMSTRONG, W. (ed) Moral psychology, volume 2: the cognitive science of morality: intuition and diversity. Cambridge: The MIT Press, pp. 47-76.

Velloso, C. (2009). Julgamentos devem ser editados antes de transmitidos. Disponivel em <http:// www.conjur.com.br/2009-mai-02/expor-debates-stf-tv-justica-excelente-depois-editados>. Acesso em: 23 out. 2015.

Vojvodic, A. M.; Machado, A. M. F. \& Cardoso, E. L. C. (2009). Escrevendo um romance, primeiro capítulo: precedentes e processo decisório no STF. Revista Direito GV, São Paulo, 5(1), pp. 21-44.

Data de submissão/Submission date: 13.12.2016.

Data de aceitação para publicação/Acceptance date: 17.09.2017. 


\section{Apêndice 1}

\begin{tabular}{|c|c|}
\hline \multicolumn{2}{|l|}{ Modelo I } \\
\hline & Variável independente \\
\hline & Extensão dos debates \\
\hline \multirow[t]{2}{*}{ Houve pedido de vista? } & 0.321 \\
\hline & $(-0.477,1.120)$ \\
\hline \multirow[t]{2}{*}{ Extensão da decisão (votos) } & $0.094^{\star \star \star}$ \\
\hline & $(0.078,0.109)$ \\
\hline \multirow[t]{2}{*}{ A sessão foi televisionada? } & $0.990^{\star \star \star}$ \\
\hline & $(0.541,1.439)$ \\
\hline \multirow[t]{2}{*}{ Coesão da decisão } & $-3.425^{\star \star \star}$ \\
\hline & $(-4.545,-2.306)$ \\
\hline \multirow[t]{2}{*}{ Complexidade da classe processual } & -0.183 \\
\hline & $(-0.473,0.106)$ \\
\hline \multirow[t]{2}{*}{ Constant } & $2.727^{\star \star \star}$ \\
\hline & $(1.151,4.302)$ \\
\hline Observations & 733 \\
\hline $\mathrm{R} 2$ & 0.295 \\
\hline Adjusted R2 & 0.290 \\
\hline Residual Std. Error & $10.468(\mathrm{df}=727)$ \\
\hline F Statistic & $60.863^{\star \star \star}(\mathrm{df}=5 ; 727)$ \\
\hline Note: & ${ }^{\star} p^{\star \star} p^{\star \star \star} p<0.01$ \\
\hline
\end{tabular}

\begin{tabular}{|c|c|}
\hline \multicolumn{2}{|l|}{ Modelo II } \\
\hline & Variável independente \\
\hline & Extensão da decisão (votos) \\
\hline \multirow[t]{2}{*}{ Houve pedido de vista? } & $-3.285^{\star}$ \\
\hline & $(-6.774,0.203)$ \\
\hline \multirow[t]{2}{*}{ Extensão dos debates } & $1.793^{\star \star \star}$ \\
\hline & $(1.503,2.083)$ \\
\hline \multirow[t]{2}{*}{ A sessão foi televisionada? } & 0.184 \\
\hline & $(-1.806,2.173)$ \\
\hline \multirow[t]{2}{*}{ Coesão da decisão } & $-14.757^{\star \star \star}$ \\
\hline & $(-19.660,-9.855)$ \\
\hline \multirow[t]{2}{*}{ Complexidade da classe processual } & $1.675^{\star \star \star}$ \\
\hline & $(0.411,2.938)$ \\
\hline \multirow[t]{2}{*}{ Constant } & $19.492^{\star \star \star}$ \\
\hline & $(12.690,26.294)$ \\
\hline Observations & 733 \\
\hline $\mathrm{R} 2$ & 0.280 \\
\hline Adjusted R2 & 0.275 \\
\hline Residual Std. Error & $45.807(\mathrm{df}=727)$ \\
\hline F Statistic & $56.575^{\star \star \star}(\mathrm{df}=5 ; 727)$ \\
\hline Note: & ${ }^{\star} p^{\star \star} p^{\star \star \star} p<0.01$ \\
\hline
\end{tabular}




\section{Apêndice 2}

\begin{tabular}{|c|c|}
\hline \multicolumn{2}{|l|}{ Modelo Ib } \\
\hline & Variável independente \\
\hline & $\begin{array}{l}\text { Extensão dos debates (agre- } \\
\text { gado) }\end{array}$ \\
\hline \multirow[t]{2}{*}{ Houve pedido de vista? } & 2.124 \\
\hline & $(-3.994,8.242)$ \\
\hline \multirow[t]{2}{*}{$\begin{array}{l}\text { Extensão da decisão (votos, } \\
\text { agregado) }\end{array}$} & $1.104^{\star \star \star}$ \\
\hline & $(0.943,1.266)$ \\
\hline \multirow[t]{2}{*}{ A sessão foi televisionada? } & $7.151^{\star \star \star}$ \\
\hline & $(3.712,10.589)$ \\
\hline \multirow[t]{2}{*}{ Coesão da decisão } & $-16.730^{\star \star \star}$ \\
\hline & $(-25.449,-8.011)$ \\
\hline \multirow[t]{2}{*}{$\begin{array}{l}\text { Complexidade da classe pro- } \\
\text { cessual }\end{array}$} & -0.446 \\
\hline & $(-2.661,1.769)$ \\
\hline \multirow[t]{2}{*}{ Constant } & $12.802^{\star \star}$ \\
\hline & $(0.754,24.850)$ \\
\hline Observations & 733 \\
\hline $\mathrm{R} 2$ & 0.297 \\
\hline Adjusted R2 & 0.292 \\
\hline Residual Std. Error & $80.300(\mathrm{df}=727)$ \\
\hline F Statistic & $61.366^{\star \star \star}(\mathrm{df}=5 ; 727)$ \\
\hline Note: & ${ }^{\star} p^{\star \star \star} p^{\star \star \star} p<0.01$ \\
\hline
\end{tabular}

\begin{tabular}{|c|c|}
\hline \multicolumn{2}{|l|}{ Modelo IIb } \\
\hline & Variável independente \\
\hline & $\begin{array}{l}\text { Extensão da decisão (votos, } \\
\text { agregado) }\end{array}$ \\
\hline Houve pedido de vista? & -1.185 \\
\hline
\end{tabular}

\begin{tabular}{|c|c|}
\hline & $(-3.649,1.278)$ \\
\hline \multirow{2}{*}{$\begin{array}{l}\text { Extensão dos debates (agre- } \\
\text { gado) }\end{array}$} & $0.179^{\star \star \star}$ \\
\hline & $(0.153,0.205)$ \\
\hline \multirow[t]{2}{*}{ A sessão foi televisionada? } & -0.266 \\
\hline & $(-1.666,1.135)$ \\
\hline \multirow[t]{2}{*}{ Coesão da decisão } & $-13.322^{\star \star \star}$ \\
\hline & $(-16.734,-9.911)$ \\
\hline \multirow[t]{2}{*}{$\begin{array}{l}\text { Complexidade da classe } \\
\text { processual }\end{array}$} & 0.408 \\
\hline & $(-0.484,1.300)$ \\
\hline \multirow[t]{2}{*}{ Constant } & $13.962^{\star \star \star}$ \\
\hline & $(9.202,18.722)$ \\
\hline Observations & 733 \\
\hline R2 & 0.324 \\
\hline Adjusted R2 & 0.320 \\
\hline Residual Std. Error & $32.345(\mathrm{df}=727)$ \\
\hline F Statistic & $69.777^{\star \star \star}(\mathrm{df}=5 ; 727)$ \\
\hline Note: & ${ }^{\star} p^{\star \star} p^{\star \star \star} p<0.01$ \\
\hline
\end{tabular}

\section{Apêndice 3}

\begin{tabular}{|l|l|}
\hline \multicolumn{2}{|l|}{ Modelo III, debates até 2001} \\
\hline & Variável independente \\
\hline & Extensão dos debates \\
\hline & \\
\hline Houve pedido de vista? & -0.222 \\
\hline & $(-0.797,0.353)$ \\
\hline & \\
\hline Extensão da decisão (votos) & $0.034^{\star \star \star}$ \\
\hline & $(0.020,0.047)$ \\
\hline & \\
\hline Coesão da decisão & $-1.173^{\star \star \star}$ \\
\hline & $(-1.960,-0.386)$ \\
\hline & \\
\hline Complexidade da classe processual & $0.187^{\star}$ \\
\hline & $(-0.021,0.396)$ \\
\hline
\end{tabular}




\begin{tabular}{|l|l|}
\hline & \multicolumn{2}{|l|}{} \\
\hline Constant & 0.262 \\
\hline & $(-0.872,1.395)$ \\
\hline & \multicolumn{2}{|l|}{} \\
\hline \multicolumn{2}{|l|}{} \\
\hline Observations & 337 \\
\hline R2 & 0.114 \\
\hline Adjusted R2 & 0.103 \\
\hline Residual Std. Error & $5.336(\mathrm{df}=332)$ \\
\hline F Statistic & $10.675^{\star \star *}(\mathrm{df}=4 ; 332)$ \\
\hline & \multicolumn{2}{|l}{} \\
\hline Note: & ${ }^{\star \star} \mathrm{p}^{\star \star} \mathrm{p}^{\star \star *} \mathrm{p}<0.01$ \\
\hline
\end{tabular}

\begin{tabular}{|c|c|}
\hline & $\begin{array}{l}\text { Extensão da decisão } \\
\text { (votos) }\end{array}$ \\
\hline \multirow[t]{2}{*}{ Houve pedido de vista? } & -1.183 \\
\hline & $(-5.596,3.229)$ \\
\hline \multirow[t]{2}{*}{ Extensão dos debates } & $1.978^{\star \star \star}$ \\
\hline & $(1.181,2.775)$ \\
\hline \multirow[t]{2}{*}{ Coesão da decisão } & $-8.985^{\star \star \star}$ \\
\hline & $(-15.024,-2.945)$ \\
\hline \multirow[t]{2}{*}{$\begin{array}{l}\text { Complexidade da classe proces- } \\
\text { sual }\end{array}$} & $-1.402^{*}$ \\
\hline & $(-3.004,0.200)$ \\
\hline \multirow[t]{2}{*}{ Constant } & $25.545^{\star \star \star}$ \\
\hline & $(17.293,33.798)$ \\
\hline Observations & 337 \\
\hline $\mathrm{R} 2$ & 0.111 \\
\hline Adjusted R2 & 0.100 \\
\hline Residual Std. Error & $40.938(d f=332)$ \\
\hline F Statistic & $10.381^{\star \star \star}(\mathrm{df}=4 ; 332)$ \\
\hline Note: & ${ }^{\star} p^{\star \star} p^{\star \star \star} p<0.01$ \\
\hline
\end{tabular}

\begin{tabular}{|c|c|}
\hline \multicolumn{2}{|l|}{ Modelo IV, debates a partir de 2003} \\
\hline & Variável independente \\
\hline & Extensão dos debates \\
\hline \multirow[t]{2}{*}{ Houve pedido de vista? } & 1.100 \\
\hline & $(-0.385,2.585)$ \\
\hline \multirow[t]{2}{*}{ Extensão da decisão (votos) } & $0.119^{\star \star \star}$ \\
\hline & $(0.094,0.145)$ \\
\hline \multirow[t]{2}{*}{ Coesão da decisão } & $-5.549^{\star \star \star}$ \\
\hline & $(-7.706,-3.391)$ \\
\hline \multirow[t]{2}{*}{ Complexidade da classe processual } & $-0.818^{\star \star \star}$ \\
\hline & $(-1.375,-0.261)$ \\
\hline \multirow[t]{2}{*}{ Constant } & $7.393^{\star \star \star}$ \\
\hline & $(4.363,10.423)$ \\
\hline Observations & 355 \\
\hline R2 & 0.367 \\
\hline Adjusted R2 & 0.359 \\
\hline Residual Std. Error & $13.107(\mathrm{df}=350)$ \\
\hline F Statistic & $50.641^{\star \star \star}(\mathrm{df}=4 ; 350)$ \\
\hline Note: & ${ }^{*} \mathrm{p}^{\star \star} \mathrm{p}^{\star \star \star} \mathrm{p}<0.01$ \\
\hline
\end{tabular}

\begin{tabular}{|l|l|}
\hline \multicolumn{2}{|l|}{ Modelo V, extensão dos votos até 2001} \\
\hline & Variável independente \\
\hline & \\
\hline
\end{tabular}

\begin{tabular}{|l|l|}
\hline \multicolumn{2}{|l|}{ Modelo VI, extensão dos votos a partir de 2003} \\
\hline & Variável independente \\
\hline & \\
\hline & Extensão dos debates \\
\hline Houve pedido de vista? & $-5.662^{\star \star}$ \\
\hline & $(-11.131,-0.193)$ \\
\hline Extensão da decisão (votos) & $1.629^{\star \star \star}$ \\
\hline & $(1.282,1.977)$ \\
\hline & \\
\hline Coesão da decisão & $-20.083^{\star \star \star}$ \\
\hline & $(-28.063,-12.104)$ \\
\hline & \\
\hline Complexidade da classe processual & $4.196^{\star \star \star}$ \\
\hline & $(2.161,6.231)$ \\
\hline
\end{tabular}




\begin{tabular}{|c|c|}
\hline Constant & $15.732^{\star \star \star}$ \\
\hline & $(4.300,27.163)$ \\
\hline Observations & 355 \\
\hline $\mathrm{R} 2$ & 0.378 \\
\hline Adjusted R2 & 0.371 \\
\hline Residual Std. Error & $48.408(\mathrm{df}=350)$ \\
\hline F Statistic & $53.150^{\star \star \star}(\mathrm{df}=4 ; 350)$ \\
\hline Note: & ${ }^{\star} p^{\star \star} p^{\star \star \star} p<0.01$ \\
\hline
\end{tabular}

\begin{tabular}{|c|c|}
\hline \multicolumn{2}{|c|}{ Modelo IVb, debates a partir de 2003} \\
\hline & Variável independente \\
\hline & $\begin{array}{l}\text { Extensão dos debates (agre- } \\
\text { gado) }\end{array}$ \\
\hline \multirow[t]{2}{*}{ Houve pedido de vista? } & 6.906 \\
\hline & $(-5.010,18.823)$ \\
\hline \multirow{2}{*}{$\begin{array}{l}\text { Extensão da decisão (votos, } \\
\text { agregado) }\end{array}$} & $1.347^{\star \star \star}$ \\
\hline & $(1.089,1.605)$ \\
\hline \multirow[t]{2}{*}{ Coesão da decisão } & $-35.138^{\star \star \star}$ \\
\hline & $(-52.311,-17.965)$ \\
\hline \multirow[t]{2}{*}{$\begin{array}{l}\text { Complexidade da classe pro- } \\
\text { cessual }\end{array}$} & -2.201 \\
\hline & $(-6.625,2.224)$ \\
\hline \multirow[t]{2}{*}{ Constant } & $40.663^{\star \star \star}$ \\
\hline & $(16.283,65.044)$ \\
\hline Observations & 355 \\
\hline R2 & 0.366 \\
\hline Adjusted R2 & 0.359 \\
\hline Residual Std. Error & $105.458(\mathrm{df}=350)$ \\
\hline F Statistic & $50.575^{\star \star \star}(\mathrm{df}=4 ; 350)$ \\
\hline Note: & ${ }^{\star} p^{\star \star} p^{\star \star \star} p<0.01$ \\
\hline
\end{tabular}

\section{Apêndice 4}

\begin{tabular}{|c|c|}
\hline \multicolumn{2}{|l|}{ Modelo IIIb, debates até 2001} \\
\hline & Variável independente \\
\hline & $\begin{array}{l}\text { Extensão dos debates (agre- } \\
\text { gado) }\end{array}$ \\
\hline \multirow[t]{2}{*}{ Houve pedido de vista? } & -1.863 \\
\hline & $(-4.891,1.166)$ \\
\hline \multirow[t]{2}{*}{$\begin{array}{l}\text { Extensão da decisão (votos, } \\
\text { agregado) }\end{array}$} & $0.387^{\star \star \star}$ \\
\hline & $(0.247,0.527)$ \\
\hline \multirow[t]{2}{*}{ Coesão da decisão } & $-3.720^{\star}$ \\
\hline & $(-8.124,0.685)$ \\
\hline \multirow[t]{2}{*}{$\begin{array}{l}\text { Complexidade da classe pro- } \\
\text { cessual }\end{array}$} & 0.532 \\
\hline & $(-0.565,1.630)$ \\
\hline \multirow[t]{2}{*}{ Constant } & 1.431 \\
\hline & $(-4.577,7.439)$ \\
\hline Observations & 337 \\
\hline R2 & 0.124 \\
\hline Adjusted R2 & 0.114 \\
\hline Residual Std. Error & $28.132(\mathrm{df}=332)$ \\
\hline F Statistic & $11.800^{\star \star \star}(\mathrm{df}=4 ; 332)$ \\
\hline Note: & ${ }^{\star} p^{\star \star} p^{\star \star \star} p<0.01$ \\
\hline
\end{tabular}

\begin{tabular}{|l|l|}
\hline \multicolumn{2}{|l|}{ Modelo Vb, extensão dos votos até 2001} \\
\hline & Variável independente \\
\hline & $\begin{array}{l}\text { Extensão dos debates (agre- } \\
\text { gado) }\end{array}$ \\
\hline & 0.473 \\
\hline Houve pedido de vista? & $(-1.758,2.705)$ \\
\hline & \\
\hline & $0.209^{\star \star \star}$ \\
\hline Extensão da decisão (votos, & $(0.134,0.285)$ \\
\hline ggregado) & $-10.431^{\star \star \star}$ \\
\hline
\end{tabular}




\begin{tabular}{|l|l|}
\hline & $(-13.484,-7.378)$ \\
\hline & \\
\hline $\begin{array}{l}\text { Complexidade da classe pro- } \\
\text { cessual }\end{array}$ & -0.204 \\
\hline & $(-1.012,0.604)$ \\
\hline & \\
\hline Constant & $13.395^{\star \star \star}$ \\
\hline & $(9.217,17.574)$ \\
\hline & \\
\hline & \multicolumn{2}{|l}{} \\
\hline Observations & 337 \\
\hline R2 & 0.236 \\
\hline Adjusted R2 & 0.226 \\
\hline Residual Std. Error & $20.690(\mathrm{df}=332)$ \\
\hline F Statistic & $25.591^{\star \star \star}(\mathrm{df}=4 ; 332)$ \\
\hline & \multicolumn{2}{|l}{} \\
\hline Note: & ${ }^{\star} \mathrm{p}^{\star \star} \mathrm{p}^{\star \star *} \mathrm{p}<0.01$ \\
\hline
\end{tabular}

\begin{tabular}{|l|l|}
\hline \multicolumn{2}{|l|}{ Modelo Vlb, extensão dos votos a partir de 2003} \\
\hline \multicolumn{2}{|l|}{} \\
\hline & Variável independente \\
\hline & $\begin{array}{l}\text { Extensão dos debates (agre- } \\
\text { gado) }\end{array}$ \\
\hline \multicolumn{2}{|l|}{} \\
\hline Houve pedido de vista? & -2.528 \\
\hline \multicolumn{2}{|l|}{$(-6.777,1.722)$} \\
\hline $\begin{array}{l}\text { Extensão da decisão (votos, } \\
\text { agregado) }\end{array}$ & $0.171^{\star \star \star}$ \\
\hline \multicolumn{2}{|l|}{} \\
\hline & $(0.139,0.204)$ \\
\hline Coesão da decisão & \\
\hline & $-14.761^{\star \star \star}$ \\
\hline & $(-20.831,-8.691)$ \\
\hline Complexidade da classe pro- & \\
\hline cessual & 0.682 \\
\hline & $(-0.896,2.261)$ \\
\hline Constant & $14.162^{\star \star \star}$ \\
\hline & $(5.461,22.863)$ \\
\hline F Statistic & 0.371 \\
\hline & 0.364 \\
\hline & $37.611(\mathrm{df}=350)$ \\
\hline & $51.566^{\star \star \star}(\mathrm{df}=4 ; 350)$ \\
\hline &
\end{tabular}

